\title{
TINJAUAN PERENCANAAN DINDING PENAHAN TANAH (STUDI KASUS : PEMBANGUNAN JALAN KAMPUS II UKI TORAJA)
}

\author{
Henrianto Masiku
}

Dosen UKI Toraja

\begin{abstract}
ABSTRAK
Tanah sebagai material konstruksi sekaligus sebagai tanah fondasi dari suatu konstruksi/struktur seperti bendungan urugan, tanggul sungai, tembok penahan, konstruksi pekerjaan jalan, gedung dan jembatan, memerlukan suatu persyaratan tertentu baik dari segi kekuatan maupun ekonomis. Studi ini bertujuan untuk mengetahui stabilitas dinding penahan tanah yang stabil terhadap stabilitas penggeseran, penggulingan, dan kapasitas daya dukung pada dinding penahan tanah tipe gravitasi pada lokasi jalan Kampus II UKI Toraja.

Penelitian dilakukan dalam beberapa tahapan, yaitu studi literatur, pengumpulan data sekunder, pengambilan sampel tanah di lapangan, pemeriksaan (pengujian) sampel tanah di laboratorium dan metode analisis data. Perhitungan dilakukan terhadap dimensi perencanaan dinding penahan tanah lama dengan yang baru.

Hasil perhitungan stabilitas dinding penahan tanah tipe gravitasi pada pembangunan jalan Kampus II UKI Toraja tidak aman terhadap stabilitas penggeseran (Fgs) sebesar $1,48 \leq 1,5$, tidak aman terhadap stabilitas penggulingan $(\mathrm{Fgl})$ sebesar $0,81 \leq 1,5$, dan juga tidak aman terhadap stabilitas kapasitas daya dukung sebesar $1,74 \leq 3$. Agar stabilitas dinding penahan tanah aman terhadap geser, guling dan kapasitas daya dukung, lebar pondasi $(B)=1,00$.
\end{abstract}

\section{Kata kunci : Tinjauan Perencanaan Dinding Penahan Tanah}




\section{PENDAHULUAN}

Tanah merupakan aspek penting dalam perencanaan konstruksi. Karena pada tanahlah berdiri suatu bangunan. Pembangunan dinding penahan tanah haruslah benar-benar berdasarkan perhitungan kestabilan dan faktor keselamatan, karena kesalahan yang terjadi dalam pembangunan dinding penahan tanah dapat berakibat fatal yaitu kerugian harta dan hilangnya korban jiwa.

Berdasarkan latar belakang di atas, rumusan masalah dalam penelitian ini adalah berapakah dimensi dinding penahan tanah agar aman terhadap tekanan dari luar dan gaya-gaya yang bekerja pada kontruksinya ditinjau terhadap stabilitas geser, stabilitas guling dan stabilitas daya dukung tanah?

Adapun maksud dan tujuan dari penelitian ini adalah :

- Untuk mempelajari stabilitas dinding penahan tanah.

- Untuk mengetahui kemampuan dari dinding penahan tanah pada pembangunan Jalan Kampus II UKI Toraja dengan memperhitungkan beban luar sehingga stabil terhadap gaya guling, geser, dan daya dukung tanahnya.(Studi Kasus).

- Berapa dimensi dinding penahan tanah agar stabil stabil terhadap gaya guling, geser, dan daya dukung tanahnya dengan memperhitungkan beban luar. 


\section{METODE PENELITIAN}

Secara skematis metodologi penelitian disajikan secara visual dalam bentuk bagan alir sebagai berikut :

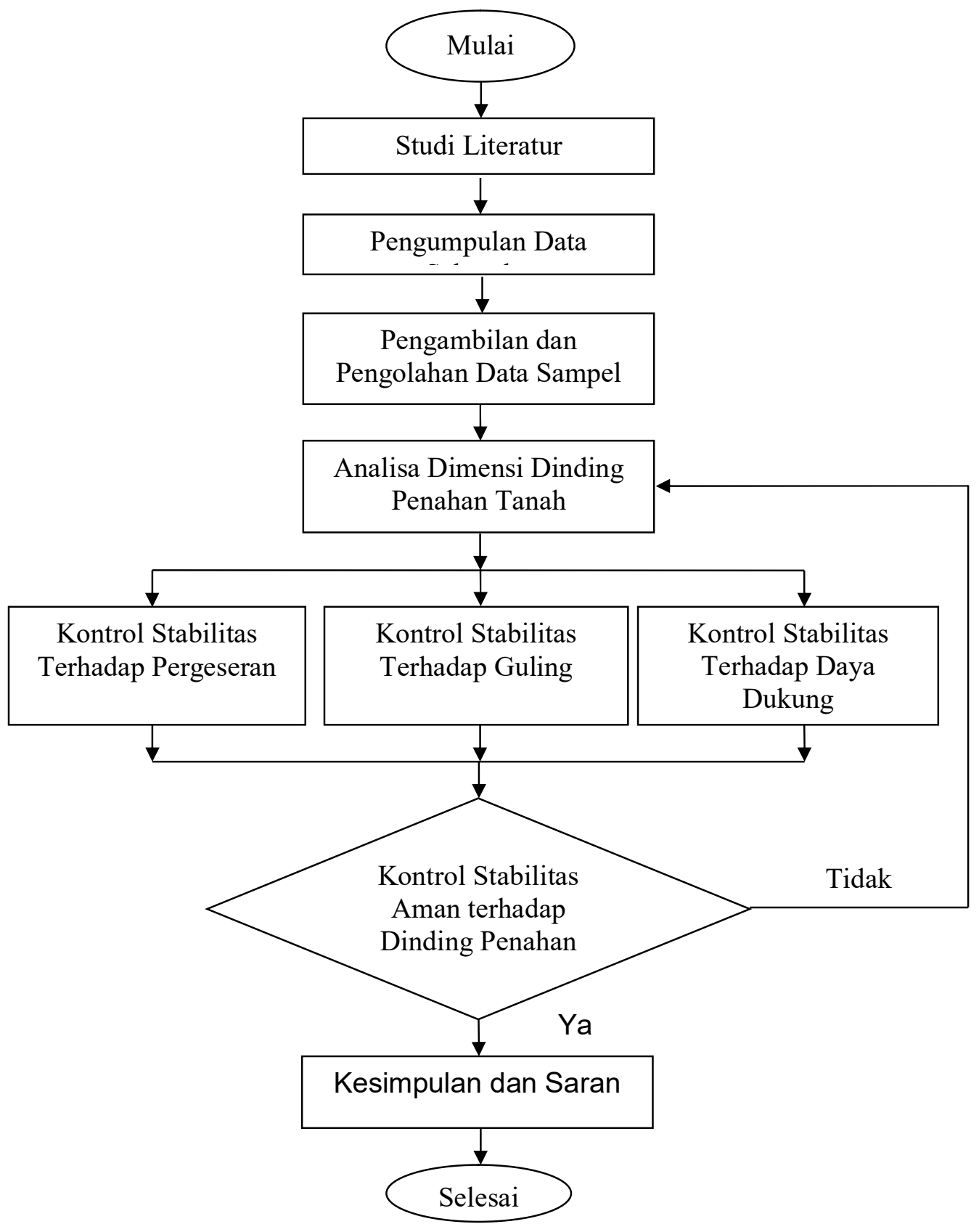

Gambar 1 Bagan alir tahapan penelitian 


\section{ANALISA DAN PEMBAHASAN}

Data tanah

Dari hasil penelitian tanah di Kantor Dinas Pekerjaan Umum Tana Toraja diperoleh data tanah sebagai berikut :

$$
\begin{array}{ll}
\text { Berat isi tanah }(\square) & =1,727 \mathrm{~g} / \mathrm{cm}^{3}=17,27 \mathrm{KN} / \mathrm{m}^{3} \\
\text { Berat volume air }\left(\square_{\mathrm{w}}\right) & =10 \mathrm{KN} / \mathrm{m}^{3} \\
\text { Sudut geser }(\phi) & =30^{\circ} \\
\text { Kohesi }(\mathrm{c}) & =0,163 \mathrm{gr} / \mathrm{cm}^{2}=16,3 \mathrm{KN} / \mathrm{m}^{2}
\end{array}
$$

Perhitungan tekanan tanah aktif dan pasif :

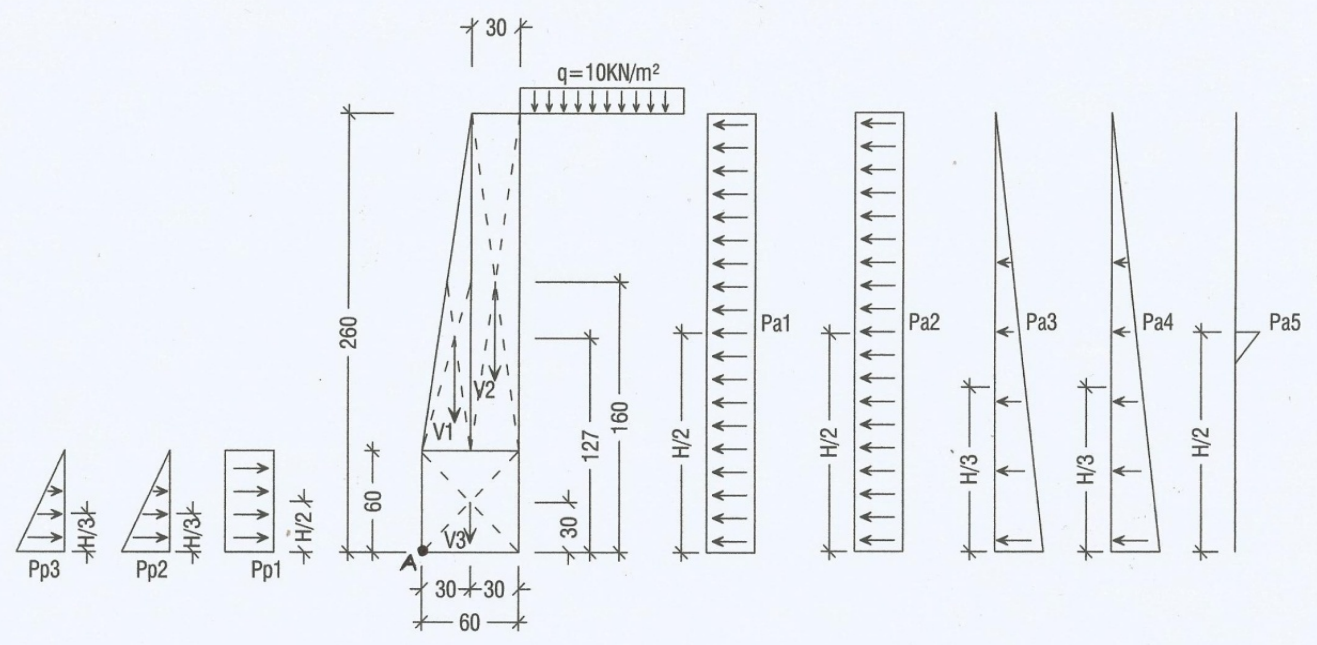

Koefisien tekanan tanah aktif :

$$
\begin{aligned}
\mathrm{K}_{\mathrm{a}} & =\tan ^{2}\left(45-\frac{30}{2}\right) \\
& =\tan ^{2} 30 \\
& =0,31
\end{aligned}
$$

Menghitung tekanan tanah aktif :

$$
\begin{aligned}
\mathrm{Pa}_{1} & =\mathrm{H}^{2} \cdot \mathrm{q} \cdot \mathrm{Ka}(\text { Akibat beban merata) } \\
& =2,60^{2} \times 10 \times 0,31 \\
& =21 \mathrm{KN} \\
\mathrm{Pa}_{2} & =-2 \cdot c \sqrt{K a} \quad \text { (Akibat kohesi tanah) }
\end{aligned}
$$




$$
\begin{aligned}
& =-2 \times 16,3 \sqrt{0,31} \\
& =-18,3 \mathrm{KN} \\
\mathrm{Pa}_{3} & =1 / 2 \cdot \mathrm{H}^{2} \cdot \square \cdot \mathrm{Ka} \quad \text { (Akibat berat isi tanah) } \\
& =1 / 2 \times 2,60^{2} \times 17,27 \times 0,62 \\
& =18,1 \mathrm{KN} \\
\mathrm{Pa}_{4} & =1 / 2 \cdot \mathrm{H}^{2} \cdot \square \mathrm{w} \quad \text { (Akibat tekanan air) } \\
& =1 / 2 \times 2,60^{2} \times 10 \\
& =33,8 \mathrm{KN} \\
\mathrm{Pa}_{5} & =\mathrm{P} \sqrt{\mathrm{Ka}} \quad(\text { Akibat berat kendaraan) } \\
& =15 \sqrt{0,31} \\
& =8,4 \mathrm{KN} \\
\sum \mathrm{Pa} & =\mathrm{Pa}_{1}+\mathrm{Pa}_{2}+\mathrm{Pa}_{3}+\mathrm{Pa}_{4}+\mathrm{Pa}_{5} \\
& =21-18,3+18,1+33,8+8,4 \\
& =63 \mathrm{KN}
\end{aligned}
$$

Menghitung momen aktif :

$$
\begin{aligned}
\mathrm{Ma}_{1} & =\mathrm{Pa}_{1}(1 / 2 \mathrm{H}) \\
& =21(2,60 / 2) \\
& =27,2 \mathrm{KNm} \\
\mathrm{Ma}_{2} & =\mathrm{Pa}_{2}(1 / 2 \mathrm{H}) \\
& =-18,3(2,60 / 2) \\
& =-23,7 \mathrm{KNm} \\
\mathrm{Ma}_{3} & =\mathrm{Pa}_{3}(1 / 3 \mathrm{H}) \\
& =18,1(2,60 / 3) \\
& =15,7 \mathrm{KNm} \\
\mathrm{Ma}_{4} & =\mathrm{Pa}_{4}(\mathrm{H} / 3) \\
& =33,8(2,60 / 3) \\
& =29,3 \mathrm{KNm} \\
\mathrm{Ma}_{5} & =\mathrm{Pa}_{5}\left(1 \frac{1}{2} \mathrm{H}\right) \\
& =8,4(2,60 / 2) \\
& =10,9 \mathrm{KNm}
\end{aligned}
$$




$$
\begin{aligned}
\Sigma \mathrm{Ma} & =\mathrm{Ma}_{1}+\mathrm{Ma}_{2}+\mathrm{Ma}_{3}+\mathrm{Ma}_{4} \\
& =27,2-23,7+15,7+29,3+10,9 \\
& =59,4 \mathrm{KNm}
\end{aligned}
$$

Sehingga besarnya lokasi resultan aktif :

$$
\begin{aligned}
\mathrm{Za} & =\frac{\sum \mathrm{Ma}}{\sum \mathrm{Pa}} \\
& =\frac{59,4}{67,6} \\
& =0,94 \mathrm{~m} \\
\mathrm{Pav} & =\mathrm{Pa} \sin 45^{\circ} \\
& =63(1 / 2 \sqrt{3}) \\
& =54,8 \mathrm{KN} / \mathrm{m} \\
\mathrm{Pah} & =\mathrm{Pa} \cos 45^{\circ} \\
& =63(1 / 2) \\
& =31,5 \mathrm{KN} / \mathrm{m}
\end{aligned}
$$

perhitungan tekanan tanah pasif :

Koefisien tekanan tanah pasif :

$$
\begin{aligned}
\mathrm{K}_{\mathrm{p}} & =\tan ^{2}\left(45+\frac{30}{2}\right) \\
& =\tan ^{2} 60 \\
& =3,23
\end{aligned}
$$

Menghitung tekanan tanah pasif :

$$
\begin{aligned}
\mathrm{Pp}_{1} & =2 \mathrm{c} \sqrt{K \overline{K p}} \quad \text { (Akibat kohesi tanah) } \\
& =2 \times 16,3 \times \sqrt{3,23} \\
& =58,7 \mathrm{KN} \\
\mathrm{Pp}_{2} & =1 / 2 \cdot \mathrm{H}^{2} \cdot \square \cdot \mathrm{Kp} \quad \text { (Akibat berat isi tanah) } \\
& =1 / 2 \times 0,60^{2} \times 17,27 \square \times 3,23 \\
& =10 \mathrm{KN} \\
\mathrm{Pp}_{3} & =1 / 2 \cdot \mathrm{H}^{2} \cdot \square \mathrm{w} \text { (Akibat tekanan air) } \\
& =1 / 2 \times 0,60^{2} \times 10 \\
& =1,8 \mathrm{KN}
\end{aligned}
$$




$$
\begin{aligned}
\sum \mathrm{Pp} & =\mathrm{Pp}_{1}+\mathrm{Pp}_{2}+\mathrm{Pp}_{3} \\
& =58,7+10+1,8 \\
& =70,5 \mathrm{KN}
\end{aligned}
$$

Menghitung momen pasif :

$$
\begin{aligned}
\mathrm{Mp}_{1} & =\mathrm{Pp}_{1}(1 / 2 \mathrm{H}) \\
& =58,7(0,60 / 2) \\
& =17,6 \mathrm{KNm} \\
\mathrm{Mp}_{2} & =\mathrm{Pp}_{2}(\mathrm{H} / 3) \\
& =10(0,60 / 3) \\
& =2,01 \mathrm{KNm} \\
\mathrm{Mp}_{3} & =\mathrm{Pp}_{3}(\mathrm{H} / 3) \\
& =1,8(0,60 / 3) \\
& =0,36 \mathrm{KNM} \\
\sum \mathrm{Mp} & =\mathrm{Mp}_{1}+\mathrm{Mp}_{2}+\mathrm{Mp}_{3} \\
& =17,6+2,01+0,36 \\
& =20 \mathrm{KNm}
\end{aligned}
$$

Sehingga besarnya lokasi resultan pasif :

$$
\begin{aligned}
\mathrm{Zp} & =\frac{\sum \mathrm{Mp}}{\sum \mathrm{Pp}} \\
& =\frac{20}{70,5} \\
& =0,28 \mathrm{~m}
\end{aligned}
$$

Perhitungan gaya-gaya vertikal akibat berat sendiri konstruksi :

$$
\begin{aligned}
\square \text { pas. batu } & =2200 \mathrm{~kg} / \mathrm{m}^{3}=22 \mathrm{KN} / \mathrm{m}^{3} \\
\mathrm{~V}_{1} \quad & =1 / 2 \times \mathrm{b}_{1} \times \mathrm{H} \times \square \text { pas. batu (Akibat berat sendiri segitiga) } \\
& =1 / 2 \times 0,60 \times 2 \times 22 \\
& =6,6 \mathrm{KN} \\
\mathrm{V}_{2} \quad & =\mathrm{b}_{2} \times \mathrm{H} \times \square \text { pas. batu (Akibat berat sendiri persegi panjang) } \\
& =0,30 \times 2 \times 22 \\
& =13,2 \mathrm{KN} \\
\mathrm{V}_{3} \quad & =\mathrm{b}_{3} \times \mathrm{H} \times \square \text { pas. batu (Akibat berat sendiri persegi panjang) }
\end{aligned}
$$




$$
\begin{aligned}
& =0,60 \times 0,60 \times 22 \\
& =7,92 \mathrm{KN}
\end{aligned}
$$

Jumlah gaya-gaya vertikal akibat berat sendiri konstruksi :

$$
\begin{aligned}
\sum \mathrm{V} & =\mathrm{V}_{1}+\mathrm{V}_{2}+\mathrm{V}_{3}+\mathrm{Pav} \\
& =6,6+13,2+7,92+54,8 \\
& =74,6 \mathrm{KN}
\end{aligned}
$$

Jarak lengan terhadap titik A :

$$
\begin{aligned}
\mathrm{X}_{1} & =2 / 3 \mathrm{~b}_{1} \\
& =2 / 3 \times 0,30 \\
& =0,2 \mathrm{~m} \\
\mathrm{X}_{2} \quad & =\mathrm{b} 1+1 / 2 \mathrm{~b}_{2} \\
& =0,30+1 / 20,30 \\
& =0,45 \mathrm{~m} \\
\mathrm{X}_{3} & =\mathrm{B} / 2 \\
& =0,60 / 2 \\
& =0,30 \\
\mathrm{XPV}_{\mathrm{V}} & =\mathrm{b}_{1}+\mathrm{b}_{2} \\
& =0,30+0,30 \\
& =0,60 \mathrm{~m}
\end{aligned}
$$

Perhitungan momen di titik A akibat gaya-gaya vertikal :

$$
\begin{aligned}
\mathrm{Mv}_{1} & =\mathrm{V}_{1} \times \mathrm{X}_{1} \\
& =6,6 \times 0,2 \\
& =1,32 \mathrm{KNm} \\
\mathrm{Mv}_{2} & =\mathrm{V}_{2} \times \mathrm{X}_{2} \\
& =13,2 \times 0,45 \\
& =5,94 \mathrm{KNm} \\
\mathrm{Mv}_{3} & =\mathrm{V}_{3} \times \mathrm{X}_{3} \\
& =7,92 \times 0,30 \\
& =2,38 \mathrm{KNm} \\
\mathrm{MPv} & =\mathrm{Pav} \times \mathrm{XPv} \\
& =54,8 \times 0,6
\end{aligned}
$$

